\title{
Trends in the incidence of primary liver cancer in Central Uganda, |960-1980 and |99|-2005
}

\author{
P Ocama ${ }^{*, 1}$, S Nambooze ${ }^{2}$, CK Opio', MS Shiels ${ }^{3}$, HR Wabinga ${ }^{2}$ and GD Kirk ${ }^{*, 3}$ \\ 'Department of Medicine, Makerere University, PO Box 7072, Kampala, Uganda; ${ }^{2}$ Department of Pathology, Makerere University, PO Box 7072 , \\ Kampala, Uganda; ${ }^{3}$ Department of Epidemiology, Johns Hopkins Bloomberg School of Public Health, 615 N Wolfe St, Baltimore, MD 21205 , USA
}

Primary liver cancer (PLC) incidence trends from Africa are unknown. Using Kampala Cancer Registry data from 1960 to 1980 and 199I to 2005, we identified 77I PLCs. Although rates were stable among men, PLC incidence among women increased $>50 \%$. Investigations of viral hepatitis, aflatoxin, obesity, and human immunodeficiency virus (HIV) may help to explain the increasing incidence of hepatocellular carcinomas (HCCs).

British Journal of Cancer (2009) I 00, 799-802. doi:10.1038/sj.bjc.6604893 www.bjcancer.com

Published online 27 January 2009

(c) 2009 Cancer Research UK

Keywords: primary liver cancer; hepatocellular carcinoma; cancer registry; Africa; gender differences; human immunodeficiency virus/ acquired immunodeficiency syndrome (HIV/AIDS)

Trends in primary liver cancer (PLC) incidence rates will generally reflect temporal changes in exposure to aetiological agents. Worldwide, and in sub-Saharan Africa in particular, the great majority of PLCs are hepatocellular carcinomas (HCCs). In North America and Europe at present, HCCs are one of the few cancers observed with increasing incidence (Taylor-Robinson et al, 1997; El-Serag, 2004; West et al, 2006), largely attributed to earlier exposure to hepatitis C virus (HCV) (Davila et al, 2004). Prevalence of obesity and diabetes has also been increasing in these populations during concurrent time periods and has been suggested as another possible aetiological factor in rising HCC rates (Calle et al, 2003; El-Serag et al, 2004).

However, trends in HCC rates from other regions are less clear. In particular, limited data exist from regions where HCCs is primarily attributable to chronic hepatitis B viral infection. In Asia, HCC rates may be declining (Goh, 1997; McGlynn et al, 2001). Reductions in HCC incidence among young children in Taiwan has been linked to nation-wide hepatitis $\mathrm{B}$ vaccination (Chang et al, 1997). In sub-Saharan Africa, hepatitis B viral infection is endemic and the attributable fraction of HCCs due to hepatitis B virus (HBV) is high ( $60 \%)$ (Kirk et al, 2004; Parkin, 2006). Further, most African countries do not routinely provide or only recently initiated hepatitis $B$ vaccination as part of their national immunisation programmes. Urbanisation, obesity, and HIV infection might also affect HCC rates in Africa. To characterise temporal trends in HCC rates within an urban African population, we evaluated cancer registry data collected in Central Uganda from 1960 through 2005.

\footnotetext{
*Correspondence: Dr P Ocama; E-mail: pocama@idi.co.ug orDr GD Kirk; E-mail: gkirk@jhsph.edu

Received 23 October 2008; revised 15 December 2008; accepted

19 December 2008; published online 27 January 2009
}

\section{MATERIALS AND METHODS}

\section{Kampala Cancer Registry}

The Kampala Cancer Registry (KCR) was established in the Department of Pathology, College of Health Sciences, Makerere University as a population-based cancer registry for Kyadondo County, Uganda, in 1951. Data were not complete during the earliest years and registration was halted in the 1980's because of political instability. The Kampala Cancer Registry cancer registration methods have been described earlier (Wabinga et al, 2000). Briefly, information on demographics, type of cancer (coded using the second edition of the International Classification of Diseases for Oncology (Percy et al, 1990)), diagnostic method, and incidence date for all cancer cases was collected from the major health units and histopathology laboratories throughout Kyadondo County through active and passive methods. Data processing is done by CANREG, a computerised cancer registration system (Cooke, 1998) in use since 1989, with entry of earlier manually collected data. Data from 1960 to 1980 and 1991 to 2005 were considered complete for the present analyses. Our analysis of deidentified registry data was not considered human-subjects research and exempted from IRB review.

\section{Case definitions}

On the basis of histology, PLC cases were categorised into HCCs, non-HCCs, and malignancy not otherwise specified (NOS). Malignancies NOS $(n=267)$ accounted for $34 \%$ of the cases; nearly all (94\%) were diagnosed clinically without histological confirmation. Concurrent with increased reliance on ultrasonography and $\alpha$-fetoprotein for HCCs clinical confirmation, the proportion of PLCs histologically confirmed as HCCs declined recently compared with the earlier time period $(86-69 \%$ in men; $90-67 \%$ in women). To estimate HCC trends appropriately, we 
assumed that many malignancies NOS would have been classified as HCCs, had histological confirmation been carried out. Therefore, we calculated the proportion of PLC that were histologically confirmed HCCs by sex and time period and applied these proportions to the malignancies NOS; for HCC incidence estimates, these cases were assumed to be HCCs.

\section{Statistical analysis}

The age-standardised incidence rates (ASRs) for PLC and for HCCs, stratified by sex, were estimated in two broad time periods (1960 - 1980 and 1991-2005) and six shorter intervals (1960-1966, 1967-1971, 1972-1980, 1991-1994, 1995-1997, and 1998-2005). Calendar periods were defined on the basis of a grouping used in an earlier publication (Wabinga et al, 2000). Substantial population growth occurred in Kyadondo County from 268500 residents in 1960 to 1911720 in 2005; the proportion under 45 years of age increased slightly from 89.2 to $94.0 \%$ during this period. To calculate incidence rates, annual sex- and age-specific (within 5 -year groups) population denominator estimates were interpolated based on the 1959, 1969, 1980, 1991, and 2005 census estimates, assuming constant growth rates between enumerations (Wabinga et al, 2000). Incidence rates were standardised to ageand sex-specific world population estimates for 2000 (US Census Bureau, 2007). Owing to missing age at diagnosis, 27 cases were excluded from incidence rate calculations. ASRs and standard errors were calculated (Boyle and Parkin, 1991) with estimation of 95\% confidence intervals (CIs). Incidence rate ratios (IRRs) with 95\% CIs were calculated for comparison of rates by calendar period and gender. Analyses were performed using Microsoft Excel 2003 and Intercooled Stata 8.2 (College Station, TX, USA).

\section{RESULTS}

The Kampala Cancer Registry recorded 771 PLCs during the study, including 261 (33.9\%) from 1960 to 1980 and 510 (66.1\%) from 1991 to 2005. Among the PLC cases, the median age at diagnosis was 45 years (interquartile range $(\mathrm{IQR})=33,60$; range $1-97$ ) and the maleto-female ratio was 2.1. Hepatocellular carcinoma was by far the predominant tumour type, comprising $79 \%$ of all histologically confirmed PLC. Demographic characteristics for PLC and for HCC were compared across time periods (Table 1). From 1960-1980 to 1991-2005, the median age at histologically confirmed HCC diagnosis increased slightly from 42 to 44 years. The proportion of histologically confirmed HCCs diagnosed among women doubled in the latter period compared with the earlier time period with the ratio of males to females decreasing $(3.9-1.4)$.

Incidence rates of PLC and HCC among men were relatively stable from 1960-1980 to 1991-2005 (Table 2). However, among women, HCC incidence increased $>50 \%$ during this period $(\mathrm{IRR}=1.56 ; 95 \%$ CI $1.13-2.16)$. The IRRs comparing men to women decreased from 2.32 (95\% CI $1.70-3.17$ ) in $1960-1980$ to 1.30 (95\% CI 1.04-1.63) in 1991-2005. Findings for PLC were similar to those for HCC (Table 2).

When PLC incidence was examined within smaller calendar periods, trends of increasing HCC rates were observed among both the sexes, but the increase was substantially more apparent among women (Figure 1). For both sexes, the greatest increase in PLC incidence was observed in older age groups (Figure 1), increasing around twofold among men and fourfold among women aged 45 years or older.

\section{DISCUSSION}

In an analysis of cancer registry data compiled over five decades, we describe PLC and HCC incidence rates in urban Kampala, Uganda, which are stable among men but increasing among women. The Kampala Cancer Registry provides population-based HCC incidence estimates over a much longer time period than reported earlier from Africa (Bah et al, 2001). Uniquely, these data allow examination of temporal trends and prompt exploration for underlying changes in HCC etiological agents to explain observed changes in incidence.

Although well-controlled studies of HCC etiology in Uganda have not been carried out, a large proportion will be attributable to chronic hepatitis B viral infection (Tabor et al, 1977; Parkin, 2006). In contrast to some Asian HBV-endemic countries where HCC incidence rates may be declining (Goh, 1997; McGlynn et al, 2001), our data suggest that HCC rates are increasing in Uganda. National estimates of chronic HBV prevalence in Ugandan adults is $9 \%$

Table I Demographic characteristics of primary liver cancers and histologically confirmed hepatocellular carcinoma cases in the Kampala Cancer Registry, Kyadondo County, Uganda: 1960-1980 and I991-2005

\begin{tabular}{lcccc}
\hline & \multicolumn{2}{c}{$\begin{array}{c}\text { Primary liver } \\
\text { cancer cases }\end{array}$} & $\begin{array}{c}\text { Hepatocellular } \\
\text { carcinoma cases }\end{array}$ \\
\hline $\begin{array}{l}\text { Time period } \\
N(\%)\end{array}$ & $1960-1980$ & $199 \mid-2005$ & $1960-1980$ & $199 \mid-2005$ \\
Median age (IQR) ${ }^{\mathrm{a}}$ & $26 \mid$ & 510 & $20 \mid$ & 120 \\
& $42(32,55)$ & $48(33,6 \mid)$ & $42(34,53)$ & $44(30,54)$ \\
Sex (\%) & & & & \\
Male & $205(79 \%)$ & $296(58 \%)$ & $160(80 \%)$ & $69(58 \%)$ \\
Female & $56(21 \%)$ & $214(42 \%)$ & $4 \mid(20 \%)$ & $51(43 \%)$ \\
Male: female ratio & 3.7 & 1.4 & 3.9 & 1.4 \\
\hline
\end{tabular}

${ }^{\mathrm{a}} \mathrm{QR}=$ interquartile range.

Table 2 Age-standardised incidence rates for primary liver cancer (PLC) and hepatocellular carcinoma (HCC) by gender in Kyadondo County, Uganda: $1960-1980$ and $1991-2005$

\begin{tabular}{|c|c|c|c|c|c|c|c|c|}
\hline & \multicolumn{3}{|c|}{$1960-1980$} & \multicolumn{3}{|c|}{$199 \mid-2005$} & \multirow[b]{2}{*}{ IRR:recent to early period } & \multirow[b]{2}{*}{$95 \%$ Cls } \\
\hline & $\mathbf{N}$ & $\mathbf{A S R s}^{\mathrm{a}}$ & $95 \%$ Cls & $\mathbf{N}$ & ASRs & $95 \%$ Cls & & \\
\hline \multicolumn{9}{|l|}{ PLC } \\
\hline Males & 195 & 6.96 & $5.88-8.04$ & 288 & 7.13 & $6.17-8.09$ & 1.02 & $0.83-1.26$ \\
\hline Females & 53 & 2.93 & $2.09-3.77$ & 208 & 5.33 & $4.51-6.15$ & 1.82 & $1.36-2.44$ \\
\hline IRR:males to females & & 2.38 & $1.77-3.19$ & & 1.34 & $1.09-1.64$ & & \\
\hline \multicolumn{9}{|l|}{$\mathrm{HCC}$} \\
\hline Males & 173 & 6.15 & $5.13-7.17$ & 218 & 5.38 & $4.55-6.20$ & 0.87 & $0.71-1.08$ \\
\hline Females & 49 & 2.65 & $1.85-3.44$ & 156 & 4.14 & $3.42-4.86$ & 1.56 & $1.13-2.16$ \\
\hline IRR:males to females & & 2.32 & $1.70-3.17$ & & 1.30 & $1.04-1.63$ & & \\
\hline
\end{tabular}

${ }^{\mathrm{a}} \mathrm{ASRs}=$ age-standardised incidence rates, calculated per 100000 person-years; $\mathrm{Cl}=$ confidence intervals; IRR $=$ incidence rate ratio. 

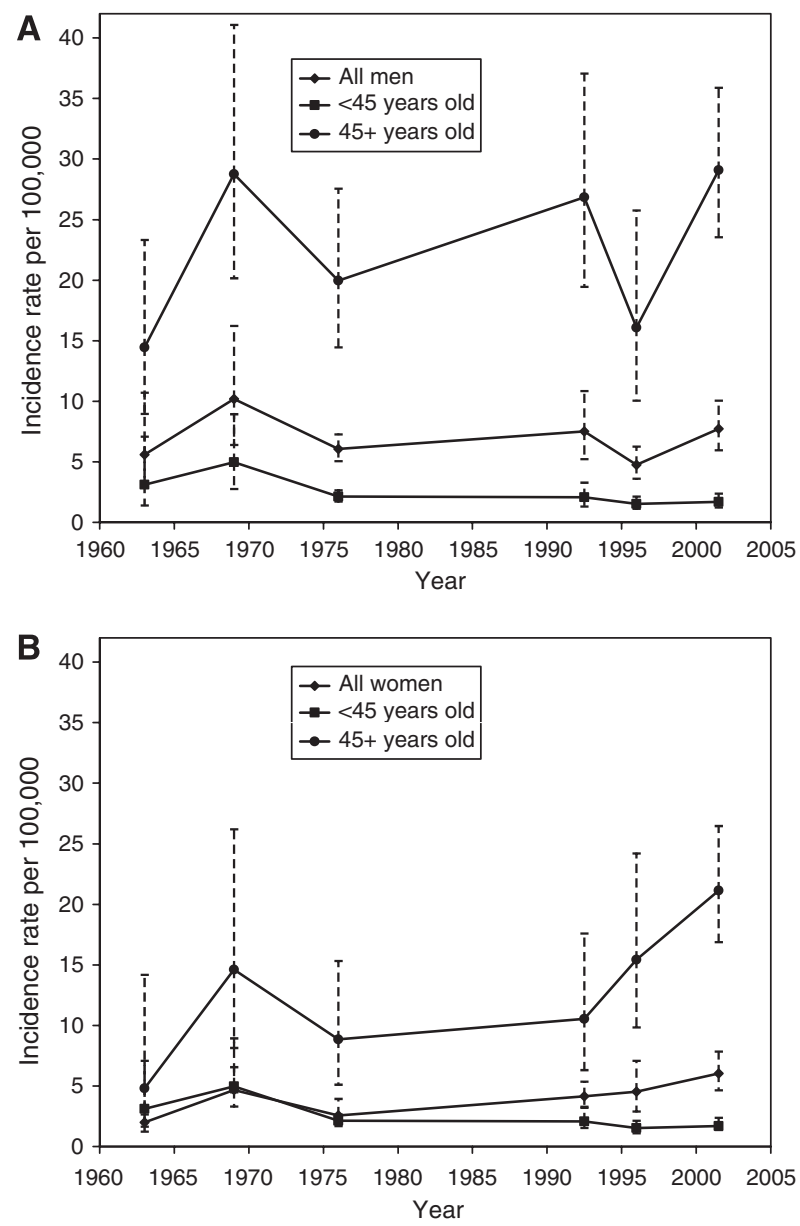

Figure I Age-standardised incidence rates of primary liver cancer among men $(\mathbf{A})$ and women $(\mathbf{B})$ overall, and stratified by age 45 years and older in Kyadondo County, Uganda: 1960-2005. Bars represent 95\% confidence intervals, calculated using a natural logarithmic transformation, around each estimate.

(MOH-Uganda, 2006). Comparing studies from earlier decades (Sadikali, 1972; Tabor et al, 1977; de Lalla et al, 1990) to the more recent ones (Nakwagala and Kagimu, 2002; Pido and Kagimu, 2005), no compelling evidence exists that HBV prevalence has changed substantively in Uganda. Notably, the male-to-female ratio in HBV-related HCCs would be expected to increase rather than decrease as we observed. Importantly, Uganda incorporated childhood vaccination against hepatitis B into their national immunisation programme in 2002, so any impact of this highly effective preventive intervention on HCC rates will not likely be observable for years.

Although increasing HCC rates in Europe and North America are largely attributed to $\mathrm{HCV}$, chronic $\mathrm{HCV}$ infection is very uncommon in Uganda (Hladik et al, 2006). Chronic HCV infection with viremia is rare even in high-risk persons (Jackson et al, 1991; Biggar et al, 2006). Although it is unlikely that HCV would fully explain the increasing HCC rates, further evaluation is warranted, particularly because PLC increases among older Ugandans are consistent with an HCV cohort effect reported from other subSaharan African populations (Kirk et al, 2006).

Dietary exposure to aflatoxin is a well-recognised cause of HCC, including an early report from Uganda (Alpert et al, 1971). Although a variety of Ugandan foods may be contaminated with aflatoxin (Kaaya and Kyamuhangire, 2006), human exposures have not been assessed. Rural to urban migrants in South Africa retained higher HCC risk, attributed in part to greater aflatoxin exposure (Kew et al, 1983; Kimbi et al, 2005). During recent decades, Kampala has been dramatically shaped by a large influx of persons migrating from rural areas.

Recent data have linked obesity and diabetes to HCC development (Calle et al, 2003; El-Serag et al, 2004; Larsson and Wolk, 2007). In Uganda, reliable population data on changes in obesity are sparse. However, in light of the relative increase in HCC among women, it is interesting to note that Ugandan women were more likely to show the association between overweight and type 2 diabetes than the generally leaner men (Lasky et al, 2002).

Data are limited on the prevalence or trends of other factors potentially influencing HCC rates. Per capita alcohol consumption in Uganda is among the highest in the world (WHO, 2004). Anecdotal evidence suggests that drinking alcohol and cigarette smoking by women have become more acceptable and increased in Uganda during recent years. Reduced parity is associated with increasing HCC risk among women ( $\mathrm{Yu}$ et al, 2003). According to the United Nations Population Division data, total fertility rates in Uganda appear to have been stable from 1970 to 1990, with subsequent small annual declines of around $0.5 \%$ from 1990 to 2006 .

The major demographic and health impact occurring in Uganda between 1960 and 2005 has clearly been the human immunodeficiency virus/acquired immunodeficiency syndrome (HIV/AIDS) epidemic. Although HIV will accelerate HBV or HCV disease progression, HIV-infected persons rarely survive long enough to manifest HCC in the absence of highly active antiretroviral therapy (HAART). Owing to the competing risks of AIDS, studies in the United States failed to show HCC increases among HIV-infected persons through the early HAART years (Mbulaiteye et al, 2003; Kramer et al, 2005). However, recent studies with longer follow-up have documented significant increases in liver disease (Bica et al, 2001; Salmon-Ceron et al, 2005) and suggested HCC increases (Clifford et al, 2005; Powles et al, 2006). Similar to pre-HAART data from developed countries, earlier Ugandan studies have not shown an increased HCC risk associated with HIV (Wabinga et al, 2000; Mbulaiteye et al, 2006). HAART was introduced in Uganda in 2003-2004; therefore, neither those earlier studies nor the current analysis would reflect HAART effects. Our evidence that HCC rates appear to be increasing before any observable HAART-related effect raises considerable concern that the burden of HCCs may expand substantially in future years (Powles et al, 2006).

Limitations of cancer registry data collected in a resourcelimited settings have been discussed in detail earlier (Wabinga et al, 2000). In brief, the completeness of KCR cancer registration was formally estimated at $93 \%$ for HCC cases (Parkin et al, 2001). However, observed HCC rates were lower than in some other HBVendemic regions, suggesting possible under-ascertainment. We did observe temporal changes in HCC diagnostic methods with decreased reliance on liver biopsy. However, in HBV-endemic regions the HCC case definition utilising clinical criteria, ultrasound, and $\alpha$-fetoprotein has high predictive accuracy and excellent specificity (Ho and Johnson, 1999). Although concerns regarding the accuracy of population denominator estimates interpolated from periodic census enumerations can be raised, it seems unlikely that estimates would have been differential by gender to account for the observed sex differences.

In conclusion, we present long-term cancer registry data from Uganda suggesting stable HCC incidence among men with increasing rates among women. With the potential for increasing HCC rates after prolonged survival of effectively treated HIV-infected persons, continued HCC surveillance will be vital to monitor trends. Irrespective of gender, HCCs present at very advanced stages and are highly lethal (Gondos et al, 2005). Therefore, systematic investigation of HCC etiological factors in Uganda is needed to inform appropriate primary preventive interventions (e.g., hepatitis $\mathrm{B}$ vaccine, aflatoxin reduction programmes, dietary, or physical activity interventions to prevent obesity). 


\section{ACKNOWLEDGEMENTS}

We would like to thank the clinical and medial records staff of Mulago, Rubaga, St Raphael of St Francis (Nsambya), and Mengo Hospitals for their continued assistance and cooperation with the

\section{REFERENCES}

Alpert ME, Hutt MS, Wogan GN, Davidson CS (1971) Association between aflatoxin content of food and hepatoma frequency in Uganda. Cancer 28: $253-260$

Bah E, Parkin DM, Hall AJ, Jack AD, Whittle H (2001) Cancer in the Gambia: 1988-97. Br J Cancer 84: $1207-1214$

Bica I, McGovern B, Dhar R, Stone D, McGowan K, Scheib R, Snydman DR (2001) Increasing mortality due to end-stage liver disease in patients with human immunodeficiency virus infection. Clin Infect Dis 32: $492-497$

Biggar RJ, Ortiz-Conde BA, Bagni RK, Bakaki PM, Wang CD, Engels EA, Mbulaiteye SM, Ndugwa CM (2006) Hepatitis C virus genotype 4 in Ugandan children and their mothers. Emerg Infect Dis 12: $1440-1443$

Boyle P, Parkin DM (1991) Cancer registration: principles and methods. Statistical methods for registries. IARC Sci Publ 95: 126-158

Calle EE, Rodriguez C, Walker-Thurmond K, Thun MJ (2003) Overweight, obesity, and mortality from cancer in a prospectively studied cohort of U.S. adults. $N$ Engl J Med 348: $1625-1638$

Chang MH, Chen CJ, Lai MS, Hsu HM, Wu TC, Kong MS, Liang DC, Shau WY, Chen DS (1997) Universal hepatitis B vaccination in Taiwan and the incidence of hepatocellular carcinoma in children. Taiwan Childhood Hepatoma Study Group. N Engl J Med 336: 1855-1859

Clifford GM, Polesel J, Rickenbach M, Dal Maso L, Keiser O, Kofler A, Rapiti E, Levi F, Jundt G, Fisch T, Bordoni A, De Weck D, Franceschi S (2005) Cancer risk in the Swiss HIV Cohort Study: associations with immunodeficiency, smoking, and highly active antiretroviral therapy. J Natl Cancer Inst 97: 425-432

Cooke A (1998) CANREG3 Manual. Internal Report No. 98/03. International Agency for Research on Cancer: Lyon

Davila JA, Morgan RO, Shaib Y, McGlynn KA, El-Serag HB (2004) Hepatitis $\mathrm{C}$ infection and the increasing incidence of hepatocellular carcinoma: a population-based study. Gastroenterology 127: 1372-1380

de Lalla F, Rizzardini G, Rinaldi E, Santoro D, Zeli PL, Verga G (1990) HIV, HBV, delta-agent and Treponema pallidum infections in two rural African areas. Trans $R$ Soc Trop Med Hyg 84: 144-147

El-Serag HB (2004) Hepatocellular carcinoma: recent trends in the United States. Gastroenterology 127: S27-S34

El-Serag HB, Tran T, Everhart JE (2004) Diabetes increases the risk of chronic liver disease and hepatocellular carcinoma. Gastroenterology 126: 460-468

Goh KT (1997) Prevention and control of hepatitis B virus infection in Singapore. Ann Acad Med Singapore 26: 671-681

Gondos A, Brenner H, Wabinga H, Parkin DM (2005) Cancer survival in Kampala, Uganda. Br J Cancer 92: 1808-1812

Hladik W, Kataaha P, Mermin J, Purdy M, Otekat G, Lackritz E, Alter MJ, Downing R (2006) Prevalence and screening costs of hepatitis $C$ virus among Ugandan blood donors. Trop Med Int Health 11: 951 - 954

Ho SKW, Johnson PJ (1999) Tumor markers. In Hepatocellular Carcinoma: Contemporary Diagnosis, Investigation and Management, Leong AS-Y, Liew CT, Lau JWY, Johnson PJ (eds), pp 31-41. Oxford University Press Inc.: New York, NY

Jackson JB, Guay L, Goldfarb J, Olness K, Ndugwa C, Mmiro F, Kataaha P, Allain JP (1991) Hepatitis C virus antibody in HIV-1 infected Ugandan mothers. Lancet 337: 551

Kaaya AN, Kyamuhangire W (2006) The effect of storage time and agroecological zone on mould incidence and aflatoxin contamination of maize from traders in Uganda. Int J Food Microbiol 110: 217-223

Kew MC, Rossouw E, Hodkinson J, Paterson A, Dusheiko GM, Whitcutt JM (1983) Hepatitis B virus status of southern African Blacks with hepatocellular carcinoma: comparison between rural and urban patients. Hepatology 3: 65-68

Kimbi GC, Kew MC, Yu MC, Arakawa K, Hodkinson J (2005) 249ser p53 mutation in the serum of black southern African patients with hepatocellular carcinoma. J Gastroenterol Hepatol 20: 1185-1190

Kirk GD, Bah E, Montesano R (2006) Molecular epidemiology of human liver cancer: insights into etiology, pathogenesis and prevention from The Gambia, West Africa. Carcinogenesis 27: 2070-2082
Kampala Cancer Registry. PO is the recipient of a Sewankambo Fellowship. MSS was supported by a National Institutes of Health National Research Service Award (T32 CA009314). GDK received a pilot grant from the Johns Hopkins Center for AIDS Research which provided partial support for this study (NIH P30AI42855).

Kirk GD, Lesi OA, Mendy M, Akano AO, Sam O, Goedert JJ, Hainaut P, Hall AJ, Whittle H, Montesano R (2004) The Gambia Liver Cancer Study: infection with hepatitis $\mathrm{B}$ and $\mathrm{C}$ and the risk of hepatocellular carcinoma in West Africa. Hepatology 39: 211-219

Kramer JR, Giordano TP, Souchek J, Richardson P, Hwang LY, El-Serag HB (2005) The effect of HIV coinfection on the risk of cirrhosis and hepatocellular carcinoma in US veterans with hepatitis C. Am J Gastroenterol 100: 56-63

Larsson SC, Wolk A (2007) Overweight, obesity and risk of liver cancer: a meta-analysis of cohort studies. Br J Cancer 97: 1005-1008

Lasky D, Becerra E, Boto W, Otim M, Ntambi J (2002) Obesity and gender differences in the risk of type 2 diabetes mellitus in Uganda. Nutrition 18: $417-421$

Mbulaiteye SM, Katabira ET, Wabinga H, Parkin DM, Virgo P, Ochai R, Workneh M, Coutinho A, Engels EA (2006) Spectrum of cancers among HIV-infected persons in Africa: the Uganda AIDS-Cancer Registry Match Study. Int J Cancer 118: $985-990$

Mbulaiteye SM, Parkin DM, Rabkin CS (2003) Epidemiology of AIDSrelated malignancies: an international perspective. Hematol Oncol Clin North Am 17: 673-696

McGlynn KA, Tsao L, Hsing AW, Devesa SS, Fraumeni Jr JF (2001) International trends and patterns of primary liver cancer. Int J Cancer 94: 290-296

Ministry of Health (MOH) (Uganda), ORC Macro (2006) Uganda HIV/AIDS Sero-behavioural Survey 2004-2005. Ministry of Health and ORC Macro: Calverton, MD, USA

Nakwagala FN, Kagimu MM (2002) Hepatitis B virus and HIV infections among patients in Mulago hospital. East Afr Med J 79: 68-72

Parkin DM (2006) The global health burden of infection-associated cancers in the year 2002. Int J Cancer 118: 3030-3044

Parkin DM, Wabinga H, Nambooze S (2001) Completeness in an African cancer registry. Cancer Causes Control 12: 147-152

Percy C, Van Holten V, Muir C (eds) (1990) International Classification of Diseases for Oncology. World Health Organization: Geneva, Switzerland

Pido B, Kagimu M (2005) Prevalence of hepatitis B virus (HBV) infection among Makerere University medical students. Afr Health Sci 5: 93 -98

Powles T, Macdonald D, Nelson M, Stebbing J (2006) Hepatocellular cancer in HIV-infected individuals: tomorrow's problem? Expert Rev Anticancer Ther 6: $1553-1558$

Sadikali F (1972) Hepatitis-associated antigen and acute and chronic liver disease in Uganda. East Afr Med J 49: 783-790

Salmon-Ceron D, Lewden C, Morlat P, Bevilacqua S, Jougla E, Bonnet F, Heripret L, Costagliola D, May T, Chene G (2005) Liver disease as a major cause of death among HIV infected patients: role of hepatitis $\mathrm{C}$ and B viruses and alcohol. J Hepatol 42: 799-805

Tabor E, Gerety RJ, Vogel CL, Bayley AC, Anthony PP, Chan CH, Barker LF (1977) Hepatitis B virus infection and primary hepatocellular carcinoma. J Natl Cancer Inst 58: $1197-1200$

Taylor-Robinson SD, Foster GR, Arora S, Hargreaves S, Thomas HC (1997) Increase in primary liver cancer in the UK, 1979-94. Lancet 350: $1142-1143$

US Census Bureau (2007) World Population Information: Population by Age and Sex US Ceusus Bureau. http://www.census.gov/ipc/www/idb/ worldpopinfo.html Accessed 1 December 2007

Wabinga HR, Parkin DM, Wabwire-Mangen F, Nambooze S (2000) Trends in cancer incidence in Kyadondo County, Uganda, 1960-1997. Br J Cancer 82: $1585-1592$

West J, Wood H, Logan RF, Quinn M, Aithal GP (2006) Trends in the incidence of primary liver and biliary tract cancers in England and Wales 1971 - 2001. Br J Cancer 94: 1751 - 1758

WHO (2004) Global Status Report on Alcohol 2004. World Health Organization: Geneva

Yu MW, Chang HC, Chang SC, Liaw YF, Lin SM, Liu CJ, Lee SD, Lin CL, Chen PJ, Lin SC, Chen CJ (2003) Role of reproductive factors in hepatocellular carcinoma: impact on hepatitis B- and C-related risk. Hepatology 38: $1393-1400$ 